\begin{tabular}{|c|c|c|}
\hline o de Geografia & $\begin{array}{c}\text { Revista do Departamento de Geografia } \\
\text { Universidade de São Paulo } \\
\text { www.revistas.usp.br/rdg }\end{array}$ & 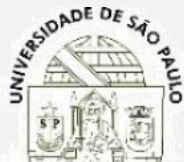 \\
\hline ISSN 2236-2878 & Volume Especial - XVII SBGFA / I CNGF (2017) & \\
\hline
\end{tabular}

\title{
Propriedades Micromorfológicas de Um Perfil de Solo na Planície Fluvial do Rio Pardo (SP): Cronologia e Processos de Alteração de Sedimentos Aluviais
}

\section{Micromorphology Features of a Soil Profile in the Pardo River Floodplain: Chronology and Weathering Processes in Alluvial Sediments.}

Francisco Sérgio Bernardes Ladeira

Universidade Estadual de Campinas

fsbladeira@ige.unicamp.br

André Luiz de Souza Celarino

Universidade Estadual do Oeste do Paraná

andrecelarino@gmail.com

Resumo: Em ambientes tropicais úmidos as taxas de pedogênese superam as de erosão/sedimentação e podem rapidamente favorecer a alteração de sedimentos nas planícies fluviais, mesmo em situações de drenagem imperfeita. $\mathrm{O}$ objetivo principal deste trabalho foi interpretar os processos pedogenéticos na planície fluvial do setor médio da bacia do rio Pardo, propondo para isso uma análise dos processos de formação de solo atuantes sobre os sedimentos aluviais e do tempo de evolução sob a ótica da micromorfologia. Para isso um perfil de solo foi descrito em campo, amostras foram coletadas para análise granulométrica pelo método da pipeta, confecção de lâminas e para a datação por LOE (Luminescência Opticamente Estimulada). Os resultados mostraram que um Gleissolo evoluiu em menos de 1000 anos sobre os sedimentos aluviais, apresentando horizontes B com estrutura prismática, além disso, processos de pedalização, gleização e uma incipiente plintização puderam ser identificados através da análise micromorfológica.

Palavras-chave: Micromorfologia de solos, intemperismo, Gleissolo, Bacia do Rio Pardo.

\begin{abstract}
Rates of soil formation exceed erosion/sedimentation in the humid tropics and might favor sediment weathering in floodplains even in poorly drained soils. The main objective of this study was to interpret the pedogenetic evolution in the floodplain of a portion in the Pardo river basin, proposing an analysis of the soil forming processes of the alluvial sediments on a time scale, focusing on micromorphology features. A soil profile was described and sampled in the field, grain size (pipette method), soil thin sections and optically stimulated luminescence (OSL) datings were obtained in laboratory. Results showed that $B$ horizons with prismatic structure developed in a Gleysol in less than 1000 years from alluvial sediments, moreover, horizonation, gleization and an incipient process of laterization could be identified from soil micromorphology analysis in thin sections.
\end{abstract}

Keywords: Soil micromorphology, weathering, Gleysol, Pardo Basin. 


\section{INTRODUÇÃO}

As planícies fluviais são feições deposicionais do vale de um canal associadas a um regime climático ou hidrológico particular da bacia de drenagem. Os sedimentos são temporariamente estocados na planície e uma alteração das condicionantes de equilíbrio, seja por processos tectônicos ou por mudanças no regime hidrológico, incluindo mudanças no aporte e transporte de sedimentos, pode levar a agradação ou degradação e formação de terraços (LEOPOLD et al., 1964; ROCHA, 2011).

Nos sistemas tropicais, as taxas de pedogênese podem superar as de erosão/sedimentação e podem rapidamente favorecer a alteração de sedimentos nas planícies fluviais (ZIELHOFER et al., 2009; CELARINO E LADEIRA, 2017). Posteriormente, os perfis de solos desenvolvidos no período anterior podem ser enterrados por depósitos fluviais (DANIELS, 2003), ou haver acúmulo de matéria orgânica devido a uma série de processos. Portanto, a combinação entre processos geomorfológicos e pedológicos é característica das planícies fluviais (BULLINGER-WEBER E GOBAT, 2006), sendo um importante marco estratigráfico que contêm mudanças ocorridas nas mais variadas escalas geológicas de tempo.

Numa seção vertical de um perfil aluvial ocorre uma sequência de depósitos de overbank, ou seja, materiais mais finos que podem ser alterados pela pedogênese em situações climáticas distintas, sendo definidos como paleossolos. Como os paleossolos não são restritos ao ambiente aluvial, o termo mais correto utilizado, nesta condição, seria pedofácies, que denota variações no grau de alteração dos solos em função da distância das áreas de alta taxa de sedimentação (BOWN E KRAUS, 1987).

O objetivo deste trabalho foi interpretar os processos pedogenéticos na planície fluvial do setor médio da bacia do rio Pardo, propondo para isso uma análise conjunta entre fácies sedimentares e feições pedológicas, enfocando processos na escala micromorfológica.

\section{METODOLOGIA}

\section{Área de estudo e métodos de campo}

A área de estudo abrange a porção média da bacia hidrográfica do rio Pardo, especificamente a área da fazenda experimental do Instituto Agronômico de Campinas entre os municípios de Mococa-SP e Arceburgo-MG (Figura 1).

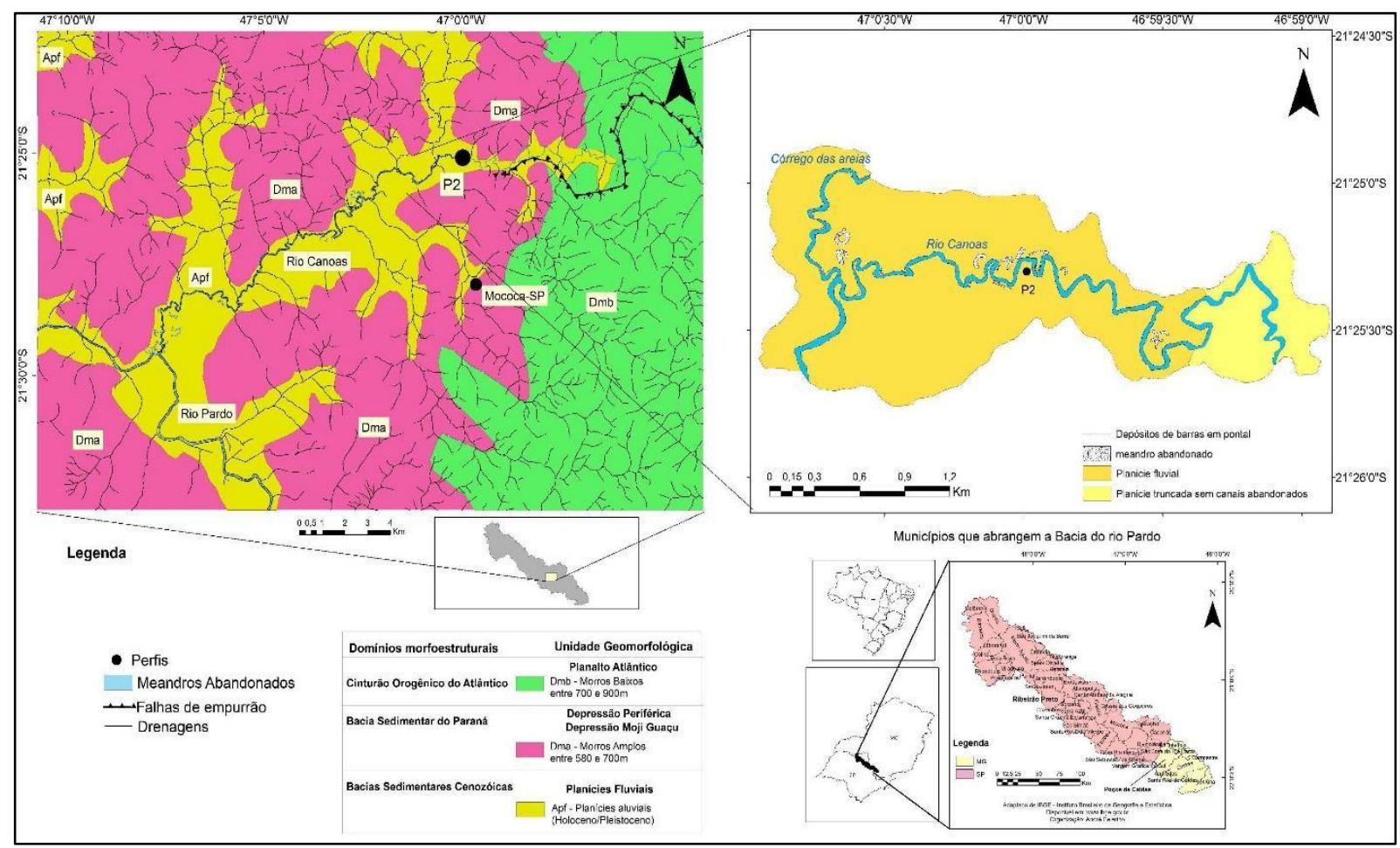

Figura 1: Mapa geomorfológico regional do médio curso do rio Pardo. 
A área do alto Pardo situa-se em áreas da província Mantiqueira (Escudo Atlântico), onde predominam rochas os complexos Varginha-Guaxupé, constituídos por granulitos migmatizados e intrudidos por granitos (ALMEIDA et al., 1976), que segundo Melo et al. (1993), correspondem a terrenos antigos de alto grau metamórfico bordejados por uma faixa de dobramentos mais jovem (faixa alto rio Grande). $\mathrm{O}$ limite oeste dessas unidades cristalinas corresponde ao limite com os sedimentos paleozóicos e vulcânicas mesozóicas associadas à Bacia do Paraná, já no médio e baixo curso do rio Pardo, objeto de estudo deste trabalho. No domínio da bacia do Paraná, as formações geológicas de maior importância no âmbito da bacia do rio Pardo são: Aquidauana, Tatuí, Corumbataí, Pirambóia, Botucatu, Serra Geral, Itaqueri e Rio Claro.

A descrição das feições pedológicas em campo seguiu o manual de descrição de coletas de solo em campo de Santos et al. (2005). Serão apresentados dados referentes ao perfil 2, embora 14 deles tenham sido abertos ao longo da bacia, sendo 6 em trincheiras e 8 através de sondagens A classificação dos horizontes pedológicos foi baseada no sistema brasileiro de classificação de solos publicado pela Embrapa (2006), levando-se em conta as interpretações realizadas em campo, os dados de granulometria e posteriormente a análise micromorfológica.

\section{Análises Laboratoriais}

Para a análise granulométrica, seguiu-se a metodologia descrita em Camargo et al. (1996). Após eliminação de matéria orgânica com $\mathrm{H}_{2} \mathrm{O}_{2}$, as amostras foram submetidas à agitação por 24hs com agente dispersante $(\mathrm{NaOH})$ e seguiu-se para a pipetagem da fração argila seguindo os intervalos de tempo da Lei de Stokes. Calculou-se o peso da fração argila após secagem em estufa $(<0,002 \mathrm{~mm})$. A fração areia foi passada na peneira após secagem em estufa e determinadas as seguintes frações: Muito Grossa $(2-1 \mathrm{~mm})$, Grossa (1$0,5 \mathrm{~mm})$, Média $(0,5-0,25 \mathrm{~mm})$, Fina $(0,25-0,1 \mathrm{~mm})$ e Muito Fina $(0,1-0,05 \mathrm{~mm})$. O silte $(0,05-0,002 \mathrm{~mm})$ foi determinado por diferença percentual. As classes texturais foram determinadas seguindo o manual da Embrapa (2006).

A coleta para a datação por luminescência opticamente estimulada (LOE) foi realizada em tubos de PVC de $0.4 \mathrm{~m}$ de comprimento por $0.05 \mathrm{~m}$ de diâmetro, inseridos horizontalmente nos perfis e condicionados em sacos plásticos escuros para proteção contra luminosidade. Esta técnica estima a última vez em que um determinado mineral, preferencialmente quartzo ou K-feldspato, recebeu luz solar por $16 \mathrm{hs,} \mathrm{ou} \mathrm{seja,} \mathrm{é} \mathrm{um}$ marcador do momento em que o mineral foi soterrado por outro material e desde então não recebe mais energia solar. Após serem enterrados os sedimentos passam a absorver radiação ionizante (U, K, Th e Rb) e raios cósmicos, esse "sinal" é acumulado na estrutura cristalina do mineral e só pode ser apagado quando exposto novamente à luz solar (RITTENOUR, 2008).

Para a análise micromorfológica foram coletadas 3 amostras indeformadas. Foram secas ao ar por dois dias, permanecendo, em seguida, pelo mesmo tempo, em estufa a $40^{\circ} \mathrm{C}$. Colocaram-se as amostras em dessecador conectado a uma bomba pneumática, formando um sistema fechado. As amostras foram impregnadas a vácuo com resina de poliéster (diluída com solvente e adicionada de um catalisador) (FITZPATRICK, 1984; CASTRO, 2008). Em seguida, foram cortadas verticalmente orientadas e laminadas até atingirem $5 \mathrm{~mm}$ de espessura, para depois serem coladas sobre lâmina de vidro. As lâminas foram polidas até a espessura de 30 $\mu \mathrm{m}$ e então coladas às lamínulas (CASTRO, 2008). Nas descrições das lâminas foram utilizadas as terminologias de Bullock et al. (1985) e Brewer (1976).

\section{RESULTADOS}

O rio Canoas possui um canal sinuoso (Índice de sinuosidade $=1,65$ ) e bastante meandrante, é possível identificar uma série de depósitos de barras de pontal principalmente quando escava os arenitos da Formação Aquidauana já na bacia do Paraná, que coincide a unidade "morros baixos entre 700 e $900 \mathrm{~m}$ " do mapa geomorfológico (Figura 1). Foram identificadas duas associações de fácies representando dois ambientes de deposição bastante distintos. $\mathrm{Na}$ base foi identificado um depósito de areia (72\% areia média) apresentando estratificação cruzada planar que coincide com a direção do fluxo do canal atual (Figura 2). 


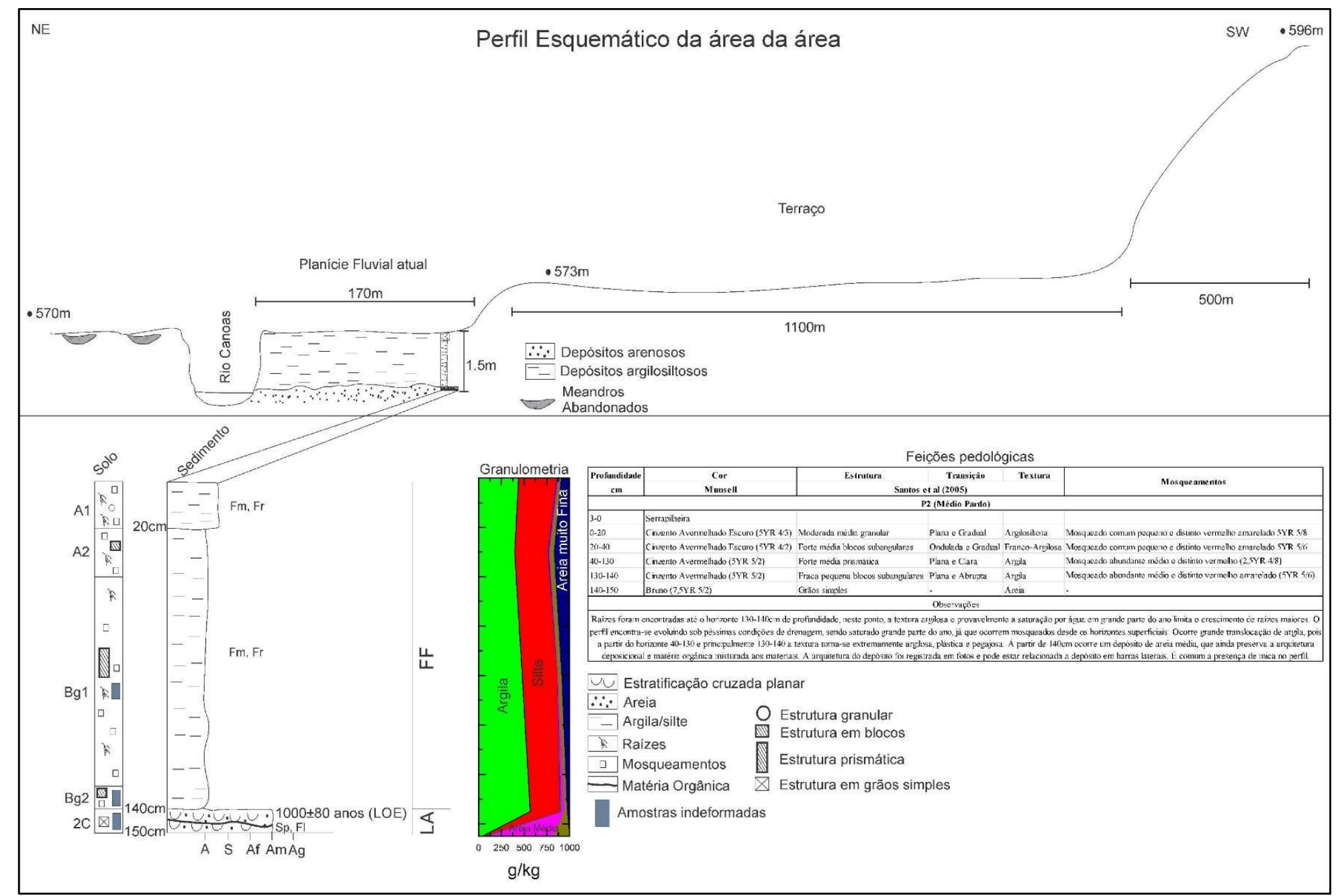

Figura 2: Feições pedológicas, fácies sedimentares e perfil esquemático do perfil 2. 
Sobre as estratificações há uma fina camada de material orgânico formando laminações concordantes com as estruturas sedimentares, trata-se de um depósito em barras de pontal (LA) de 1000 \pm 80 anos atrás apresentando duas fácies: Sp e Fl (Figura 3).

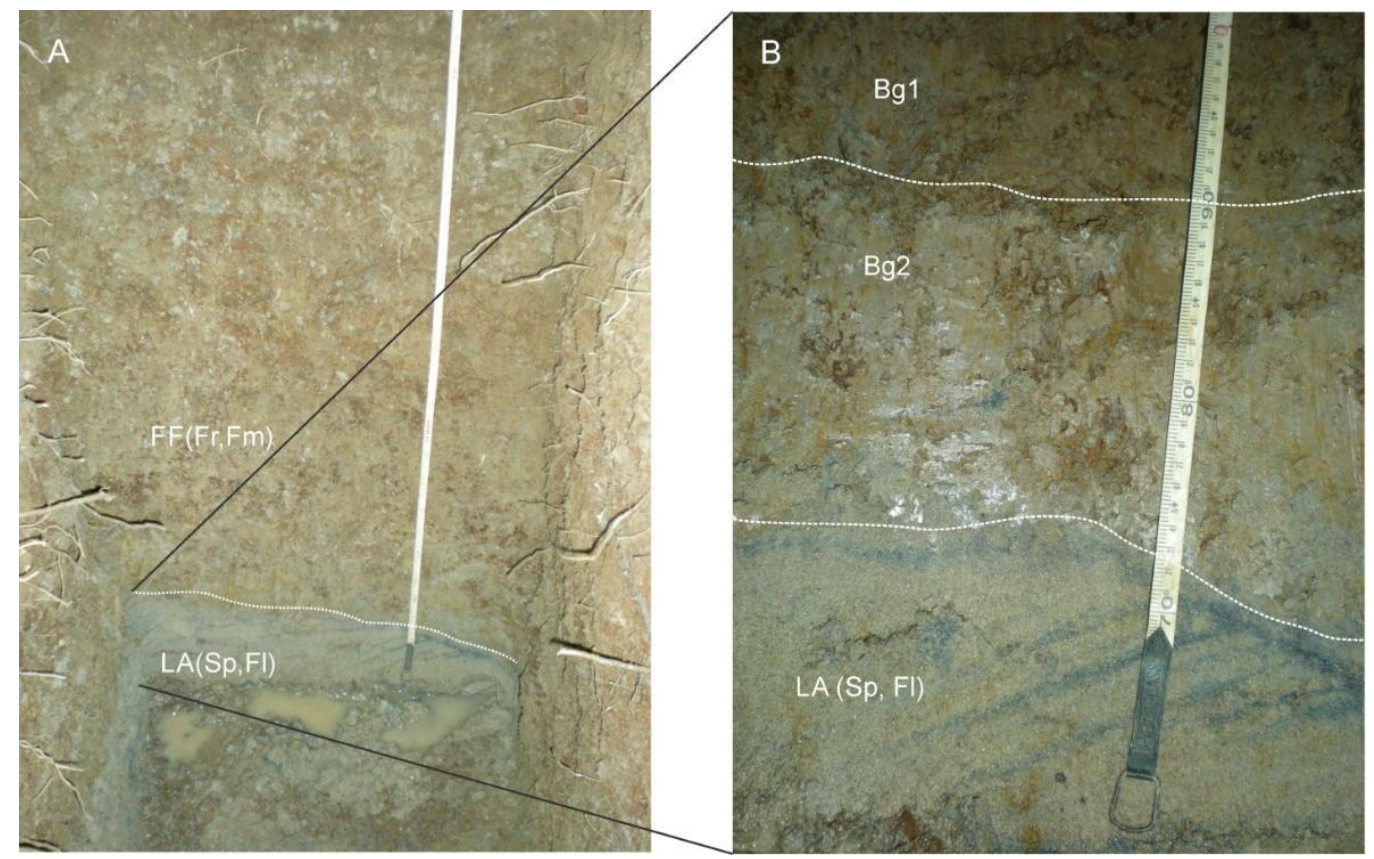

Figura 3: A - Detalhe das associações de fácies do perfil 2. B - Detalhe da estraficação cruzada planar e o desenvolvimento de horizontes pedológicos Btg nas fácies acima.

Acima deste depósito ocorre uma transição abrupta para um pacote argilosiltoso de depósitos de planície fluvial (FF) associados à sedimentação de materiais carregados em suspensão pelo rio Canoas, que apresenta significativo processo de alteração pela pedogênese e manchas de oxi-redução, indicando que esta unidade atualmente é inundada pelo transbordamento das margens do canal nos períodos mais chuvosos.

Há um terraço de mais de $1100 \mathrm{~m}$ de extensão que está $2 \mathrm{~m}$ topograficamente acima da planície de inundação atual, tal unidade provavelmente funcionava como a planície fluvial do rio Canoas quando este estava depositando as barras de pontal (fácies Sp, Fl) a 1000 \pm 80 anos atrás. A migração lateral fez com que o rio passasse a fluir em cotas menores e mais distante do terraço, proporcionando condições para depósitos mais finos (Fm, Fr) ocorressem em ambiente de planície fluvial numa posição mais distal.

A intensa alteração dos sedimentos permitiu a classificação dos horizontes pedológicos e a identificação de feições de mosqueamento abundantes, variando entre 5YR 5/6 (vermelho-amarelado) e 2,5YR 4/6 (vermelho). Os horizontes $\mathrm{Bg} 1$ e $\mathrm{Bg} 2$ apresentam estrutura forte prismática, indicando grande presença de argilominerais e significativo grau de intemperismo, no entanto, não há um aumento significativo da fração argila em relação ao horizonte A, além disso, a granulometria argilosiltosa é semelhante em ambos. Tal fato sugere que a origem dos dois horizontes é a mesma, depósitos mais finos em planície fluvial e que, a partir de uma determinada condição de estabilidade, as soluções ácidas em função da presença de matéria orgânica foram desestabilizando os minerais mais susceptíveis e desenvolvendo um horizonte A, seguido da evolução de um horizonte B em condições de hidromorfia, portanto, não caracterizando um Btg.

O depósito em barras de pontal (LA) datado em 1000 \pm 80 anos é um importante ponto de interpretação da intensidade da pedogênese, já que todo o material acima foi depositado e alterado em menos de mil anos, ou seja, bastaram $1000 \pm 80$ anos para que um perfil de solo de $150 \mathrm{~cm}$ com horizontes $\mathrm{Bg}$ de estrutura prismática e forte fosse formado.

A Tabela 1 apresenta as principais feições micromorfológicas do perfil 2. 
Tabela 1: Principais características micromorfológicas do perfil 2.

\begin{tabular}{|c|c|c|c|c|c|}
\hline \multirow[b]{2}{*}{ Horizonte } & \multirow[b]{2}{*}{ Distribuição } & \multicolumn{3}{|c|}{ Fundo matricial } & \multirow[b]{2}{*}{$\begin{array}{c}\text { Feições } \\
\text { Pedológicas }\end{array}$} \\
\hline & & Porosidade & Fração Grossa & $\begin{array}{c}\text { Fração } \\
\text { Fina }\end{array}$ & \\
\hline $\mathrm{Bg} 1$ & $\begin{array}{l}\text { Porfírica } \\
\text { Fechada }\end{array}$ & $\begin{array}{c}5 \%, \text { Pedoporos } \\
\text { intergranulares, } \\
500-1000 \mu \mathrm{m}\end{array}$ & $\begin{array}{l}\text { 30\% (80\% Quartzo, } 15 \% \\
\text { Biotitas, 5\% Opacos), } \\
\text { subarredondados, } \\
\text { subalongados, alisados e } \\
\text { moderadamente } \\
\text { selecionados }\end{array}$ & $\begin{array}{c}65 \%, \\
\text { Isotrópico }\end{array}$ & $\begin{array}{l}\text { Nódulos de Fe, } \\
\text { Acumulações de } \\
\text { M.O, pedotúbulos } \\
\text { (agrotúbulos) } \\
\text { preenchidos com } \\
\text { material do } \\
\text { esqueleto }\end{array}$ \\
\hline $\mathrm{Bg} 2$ & $\begin{array}{l}\text { Porfírica } \\
\text { Aberta }\end{array}$ & $\begin{array}{l}30 \%, \text { Bioporos e } \\
\text { Pedoporos em } \\
\text { canais e } \\
\text { cavidades } 500- \\
1000 \mu \mathrm{m}\end{array}$ & $\begin{array}{c}5 \%(85 \% \text { Quartzo, } 10 \% \\
\text { Biotitas/Muscovitas, } 5 \% \\
\text { Opacos, }<1 \% \\
\text { Clinopiroxênio), } \\
\text { subangulares, } \\
\text { subalongados, alisados e } \\
\text { moderadamente } \\
\text { selecionados }\end{array}$ & $\begin{array}{l}65 \%, \\
\text { Isotrópico } \\
\text { com zonas } \\
\text { crísticas } \\
\text { (isóticas) }\end{array}$ & $\begin{array}{l}\text { Nódulos de Fe/Al, } \\
\text { Acúmulos de } \\
\text { M.O. } \\
\text { Desenvolvimento } \\
\text { de } \\
\text { microagregados } \\
\text { incipientes. }\end{array}$ \\
\hline $2 \mathrm{C}$ & Quitônica & $\begin{array}{c}\text { 30-40\%, 1000- } \\
2000 \mu \mathrm{m}, \\
\text { Litoporos } \\
\text { intergranulares }\end{array}$ & $\begin{array}{l}\text { 50-60\% (90\% Quartzo, } \\
\text { 1\% Muscovita/Biotita, 5\% } \\
\text { Microclínio, <1\% } \\
\text { Olivina), arredondados, } \\
\text { subesféricos, alisados e } \\
\text { bem selecionados }\end{array}$ & $\begin{array}{c}10 \%, \\
\text { Isotrópico }\end{array}$ & $\begin{array}{l}\text { Poucos nódulos e } \\
\text { concreções de Fe }\end{array}$ \\
\hline
\end{tabular}

Quanto às características micromorfológicas, observa-se que no horizonte Bg1 (Tabela 1) ocorre uma distribuição porfírica fechada, com pouca porosidade (5\% da matriz), presença de nódulos de ferro e agrotúbulos preenchidos com material grosso, que é composto por $80 \%$ de quartzo, $15 \%$ de Biotitas e opacos como acessórios. A fração fina (65\% do fundo matricial) é composta por argilominerais oriundos da transformação de biotitas, identificada por uma perda de pleocroísmo e diminuição cores de interferência (ZAUYAH et al., 2010) típica de processos de pedalização observada também por Stoops e Dedecker (2006). A fração fina também apresenta feições típicas de redução de Ferro em alguns trechos da lâmina (Figura 4, A-B) ligadas à presença de água no perfil e às manchas de oxi-redução observadas na análise macroscópica. O grau de seleção da fração grossa pode ser classificado como moderado, a fração predominante fica entre 100 e $200 \mu \mathrm{m}$ (areia fina), ou seja, mesmo essa fração mais grossa (30\% do fundo matricial) é composta por grãos subarredondados e bem selecionados de uma fração mais fina, evidenciando a baixa energia de deposição destes materiais.

Ocorrem ainda algumas feições como nódulos de Ferro, pedotúbulos preenchidos pela fração grossa e por uma massa fina de cor mais acinzentada do que o material de fora, indicando processos de gleização, plintização em estágio incipiente (ELLESS E RABENHORST, 1994; AKHTAR et al., 1990) e também pedalização, pois já há a formação de microestrutura pedológica.

Já no horizonte $\mathrm{Bg} 2$ ocorre uma distribuição porfírica aberta e $30 \%$ de porosidade em relação ao fundo matricial, onde a micromassa apresentou zonas crísticas (Figura 5, A-B) típicas de um alto grau de cristalização (CASTRO, 2008). Ocorre ainda o desenvolvimento, ainda que incipiente, de uma microestrutura em algumas partes da lâmina (pedalização), isso contrasta com alguns grãos de clinopiroxênio ( $<1 \%$ dos grãos da fração grossa) encontrados, que indicariam uma alteração incipiente (Figura 4, C-D, E-F), no entanto, ressalta-se que como este setor da planície é bastante dinâmico, provavelmente enquanto os processos pedogenéticos atuavam, podem ter ocorrido novas deposições e contribuições de outros materiais concomitantemente à alteração química.

No horizonte 2C (Figura 5, C-D, E-F) observa-se uma distribuição quitônica, onde 60\% do fundo matricial faz parte da fração grossa e apresenta uma pequena película que reveste os maiores grãos. A mineralogia é composta por $90 \%$ de quartzo (Figura 5, C-D), a porosidade entre os grãos é elevada e poucas 
feições pedológicas foram encontradas. Observa-se que os grãos do esqueleto estão em geral bem selecionados e variam entre 300 e $500 \mu \mathrm{m}$ (areia média), apresentam-se ora arredondados, subesféricos, alisados e em determinados pontos estão polidos (Figura 5, E-F), tal polimento se dá pelo transporte fluvial destes sedimentos.

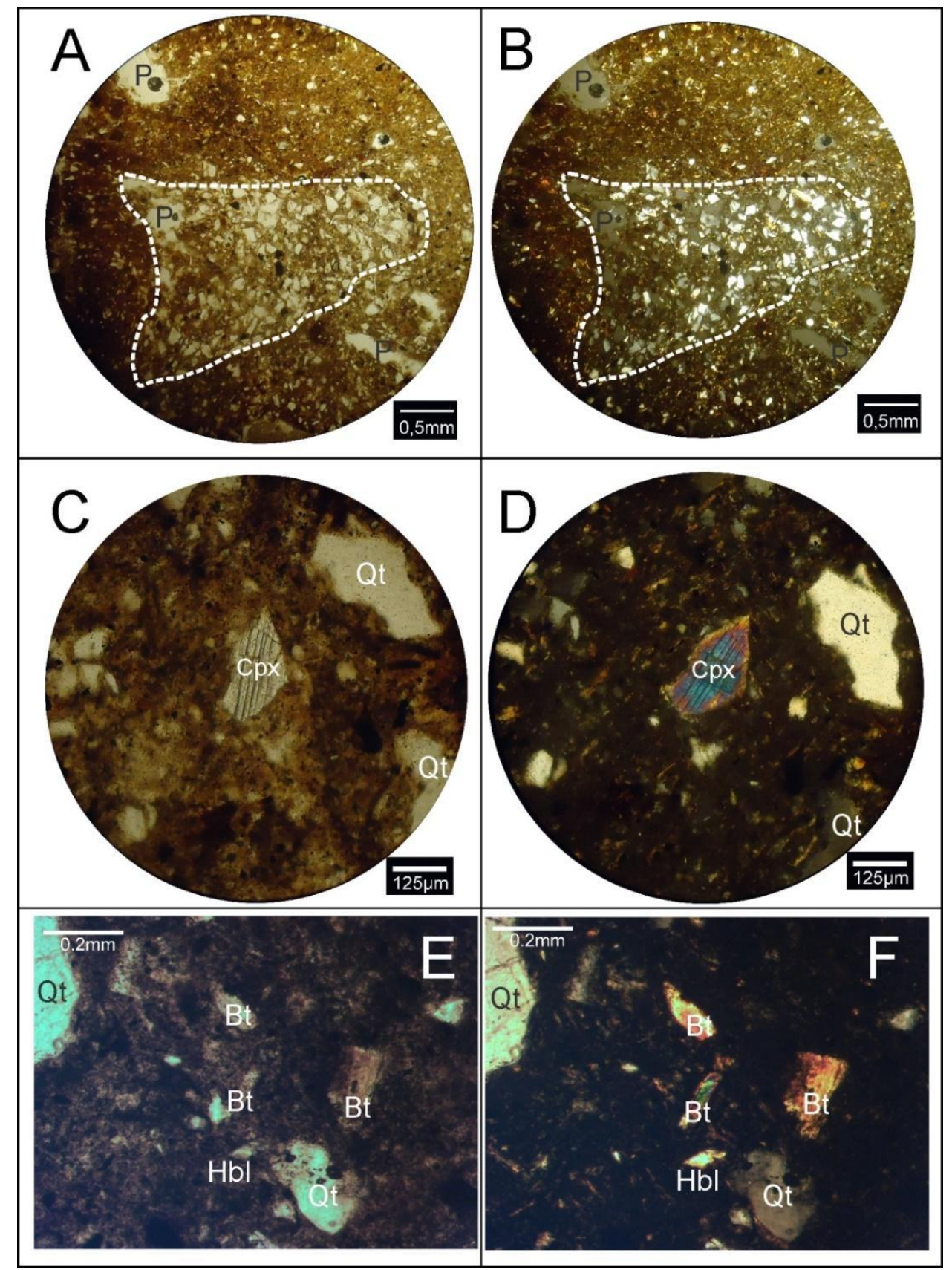

Figura 4: Fotomicrografias do perfil 2. A (LN)/ B (LPA) - Isotúbulos preenchidos por materiais grossos cimentandos pela micromassa. Micromassas de distintas composições, à esquerda observa-se uma coloração mais avermelhada devido aos óxidos de ferro, à direita do isotúbulo a micromassa é mais cinzenta, indicando fundo matricial composto por maior proporção de Ferro reduzido à sua forma $\mathrm{Fe}^{2+}(85 \mathrm{~cm}) . \mathrm{C}(\mathrm{LN}) / \mathrm{D}(\mathrm{LPA})$

- Grão do clinopiroxênio isolado apresentando alta birrefringência e superfície bastante fragmentada, indicando transporte $(130-140 \mathrm{~cm})$. E (LN)/ F (LPA) - Grãos fraturados devido à transporte e quartzo cimentados por material da micromassa rico em matéria orgânica $(130-140 \mathrm{~cm})$. Bt -Biotita, Cpx Clinopiroxênio, Hbl - Hornblenda, Qt - Quartzo, P - Poros. 


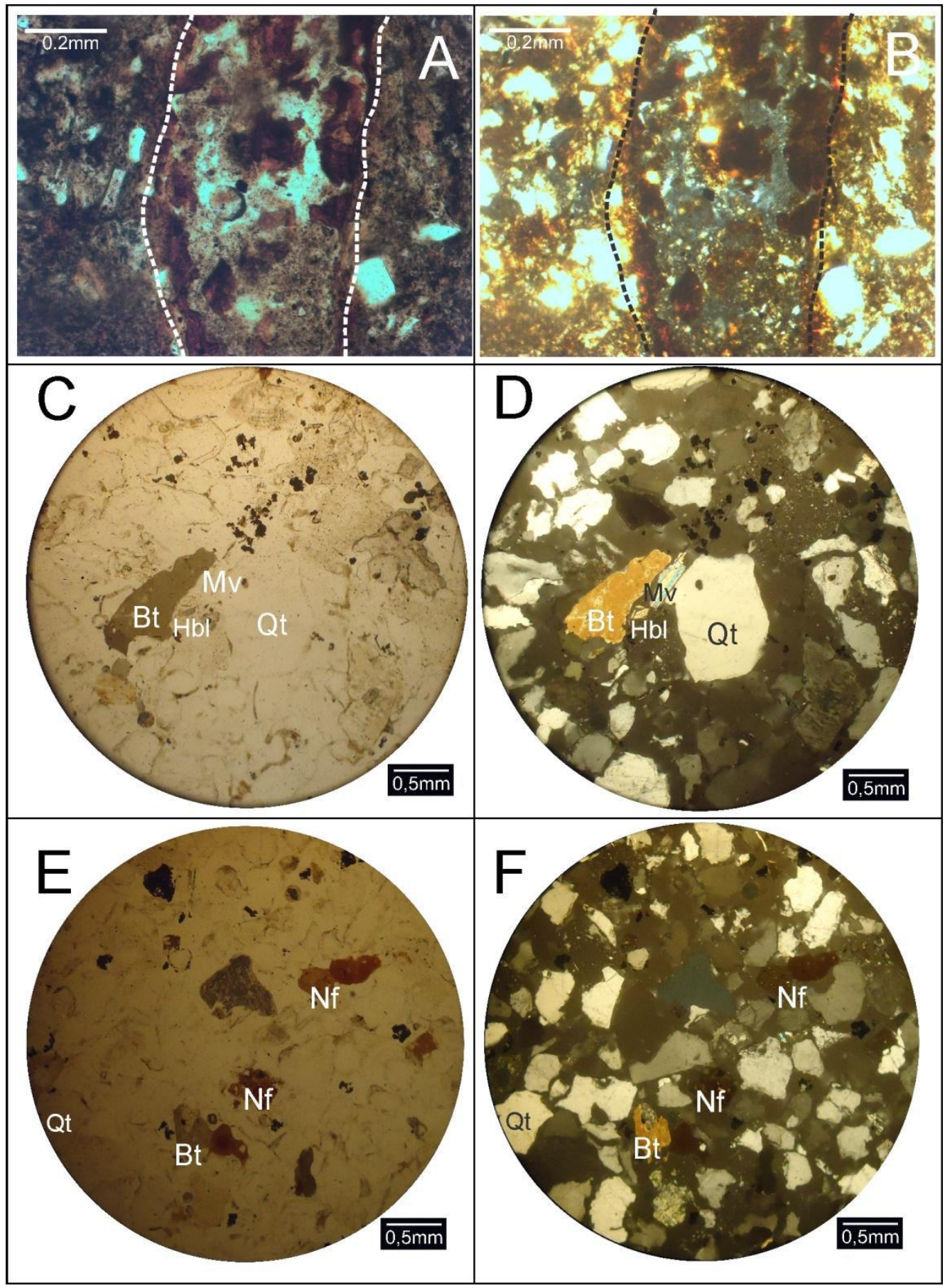

Figura 5: Fotomicrografias do perfil 2. A (LN)/ B (LPA) - Agrotúbulos preenchidos por materiais da fração grossa e micromassa associados, formando pequenos agregados. A micromassa apresenta-se localmente crística indicando alto grau de cristalização (Cristalárias) (130-140cm). C (LN)/ D (LPA) - Matriz dominada pelas frações grossas no depósito $2 \mathrm{C}$, apresentando quartzo como mineralogia principal e grãos de biotita e muscovita como acessórios (140-150cm). E (LN)/ F (LPA) - Grãos de quartzo muito bem selecionados e polidos devido ao transporte fluvial (140-150cm). Bt -Biotita, Mv - Muscovita, Hbl - Hornblenda, Qt -

Quartzo, Nf - Nódulos de Ferro.

\section{CONSIDERAÇÕES FINAIS}

O perfil 2 apresentou um depósito em barras de pontal datado em 1000 \pm 80 anos por LOE, ou seja, dentro deste período, $140 \mathrm{~cm}$ de sedimentos foram depositados e menos de mil anos foram suficientes para gerar um perfil de solo que apresentou estrutura forte nos horizontes $\mathrm{Bg} 1$ e $\mathrm{Bg} 2$, o que é relativamente baixo mesmo se comparado às idades obtidas por Zielhofer et al. (2009) para solos em planície fluvial holocênica em situação de clima mediterrâneo subtropical, onde as durações de formação variaram de 800 a 5000 anos para Cambissolos e 10.000 e 40.000 anos para Luvissolos carbonáticos. 
Apesar do pouco tempo de evolução pedogenética, foi possível observar na análise micromorfológica processos de pedalização, gleização e plintização (incipiente) nos horizontes Bg1 e Bg2, no entanto, é possível também encontrar minerais primários facilmente intemperizáveis, o que sugere um processo irregular de formação de solo ao longo do perfil. Mesmo o horizonte 2C, oriundo de um depósito em barras, já apresentou algumas feições pedológicas como pequenos nódulos de ferro, mesmo num fundo matricial onde predomina a fração grossa sobre a micromassa.

Neste trabalho foram abordadas questões básicas dos estágios iniciais de formação de solos imperfeitamente drenados sob clima tropical úmido, nesse sentido, observou-se que os modelos de evolução cronológica dos solos podem variar bastante em função do clima e do material de origem, nesse sentido, as informações levantadas nesse trabalho suscitam novas questões sobre o tempo de formação dos horizontes pedológicos e ao mesmo tempo supre algumas informações na escala micromorfológica sobre os processos pedogenéticos atuantes em depósitos fluviais.

\section{AGRADECIMENTOS}

Agradecemos à FAPESP (Fundação de Amparo à pesquisa do Estado de São Paulo) através do processo $\mathrm{n}^{\circ}$ 2011/00261-3, pelo suporte financeiro durante a bolsa no país e no exterior, e ao Instituto de Geociências da Unicamp pela estrutura fornecida nos trabalhos de campo. Ao CNPq pela Bolsa Produtividade em Pesquisa do primeiro autor.

\section{BIBLIOGRAFIA}

AKHTAR, M.S., DIXON, J.B., WILDING, L.P. Pedogenic changes and mineral weathering in three soils from the Indus river plain of Pakistan. In: DOUGLAS, L.A. (Ed). Soil micromorphology: A basic and applied science. Developments in Soil Science. Proceedings of $8^{\text {th }}$ International working meeting of Soil micromorphology, San Antonio. Elsevier, Ammsterdan, p.161-168. 1990.

ALMEIDA, F.F.M., HASUY, Y., NEVES B.B. de B. The upper Precambrian of South America. Bol. IGUSP, v.7, p.45-80. 1976.

BOWN, T. M.; KRAUS, M. J. Integration of channel and floodplain suites, I. Developmental sequence and lateral relations of alluvial paleosols. Journal of Sedimentary Petrology, v. 57, n.4, p. 587-601. 1987.

BREWER, R. Fabric and mineral analysis of soils. New York, Robert E. Krieger Publishing Company, 482p. 1976.

BULLINGER-WEBER, G., GOBAT, J.M. Identification of facies models in alluvial soil formation: The case of a Swiss alpine floodplain. Geomorphology 74, p.181-195. 2006.

BULLOCK, P., FEDOROFF, N., JONGERIUS, A., STOOPS, G., TURSINA, T. Handbook for soil thin section description. Waine Research Publications, Wolverhampton, 152p. 1985.

CAMARGO, O.A.; MONIZ, A.C.; JORGE, J.A.; VALADARES, J.M.A.S. Métodos de análise química, mineralógica e física de solos do Instituto Agronômico de Campinas. Campinas: Instituto Agronômico, (IAC, Boletim Técnico, 106). 94p. 1996.

CASTRO, S.S. Micromorfologia de Solos. Bases para descrição de lâminas delgadas. $2^{a}$ Edição. Apostila da disciplina de pós-graduação sobre Micromorfologia de Solos. Unicamp - IG - DGEO, UFG - IESA. Campinas/Goiânia, 135p. 2008.

CELARINO, A.L.S.; LADEIRA, F.S.B. How fast are soil-forming processes in Quaternary sediments of a tropical floodplain? A case study in southeast Brazil. Catena 156, p. 263-280. 2017.

DANIELS, M. Floodplain aggradation and pedogenesis in a semiarid environment. Geomorphology 56, p. 225-242. 2003.

ELLESS, M.P. e RABENHORST, M.C. Micromorphological interpretation of redox processes in soils derived from triassic redbed parent materials. In: RINGROSE-VOASE, A.J e G.S. Humphreys (Editores), Soil Micromorphology: Studies in Management and Genesis. Proc. IX Int. Working Meeting on Soil Micromorphology, Townsville, Australia, July 1992. Developments in Soil Science 22, Elsevier, Amsterdam, p. 171-178. 1994. 
EMBRAPA. Centro Nacional de Pesquisa de Solos. Sistema brasileiro de classificação de solos. $2^{\text {a }}$ Edição. Brasília: Embrapa Produção de Informação; Rio de Janeiro: Embrapa Solos, 306p. 2006.

FITZPATRICK, E.A. Micromorphology of soils. Robert E. Krieger, New York, 482p. 1984.

LEOPOLD, L.B., WOLMAN, M.G., MILLER, J.P. Fluvial processes in geomorphology. San Francisco: Freedman, 319p. 1964.

MELO, M.S. de; STEIN, D.P.; PONÇANO, W.L.; BISTRICHI, C.A. Neotectônica da área do alto rio Pardo (SP e MG). Revista do Instituto Geológico, v.14, n.2, p. 27-38. 1993.

RITTENOUR, T.M. Luminescence dating of fluvial deposits: applications to geomorphic, palaeoseismic and archaeological research. Boreas, v.37, p. 613-635. 2008.

ROCHA, P.C. Sistemas rio-planície de inundação: Geomorfologia e conectividade hidrodinâmica. Caderno Prudentino de Geografia, n.33, p. 50-67. 2011.

SANTOS, R.D.; LEMOS, R.C.; SANTOS, H.G.; KER, J.C.; ANJOS, L.H.C. Manual de descrição e coleta de solo no campo. $5^{\text {a }}$ Edição. Viçosa: SBCS, 92p. 2005.

STOOPS, G. e DEDECKER, D. Microscopy of undisturbed sediments as a help in planning dredging operations. A case study from Thailand. International Conference 'Hubs, Harbours and Deltas in Southeast Asia: Multidisciplinary and Intercultural Perspective'. Royal Academy of Overseas Sciences, Brussels, p. 193-211. 2006.

ZAUYAH, S., SCHAEFER, C.E.G.R., SIMAS, F.N.B. Saprolites. In: STOOPS, G., MARCELINO, V., MEES, F. (Eds) Interpretation of micromorphological features of soil regoliths. Oxford: Elsevier, p. 4968. 2010.

ZIELHOFER, C., ESPEJO, J.M.R., GRANADOS, M.A.N., FAUST, D. Durations of soil formation and soil development indices in a Holocene Mediterranean floodplain. Quaternary International 209, p. 44-65, 2009. 